\title{
A CRISE POLÍTICA NO PARAGUAI E O BRASIL
}

\section{Paraguay crisis and Brazil}

Cíntia Vieira Souto ${ }^{1}$

Há cerca de um mês ocorreu uma importante mudança institucional no Paraguai com o afastamento por impeachment do presidente eleito em 2008, Fernando Lugo. Duas questões se impõem diante do momento político atual no Paraguai. Por que Fernando Lugo caiu, com tamanha unanimidade e tão rápido? Em que essa mudança afeta as relações do Brasil com o Paraguai?

Em 15 de junho de 2012, as forças policiais paraguaias foram retirar um grupo de camponeses sem terra que invadira uma fazenda em Curuguaty, $250 \mathrm{~km}$ a noroeste de Assunção. Houve um confronto no qual morreram 12 camponeses e 6 policiais. $\mathrm{O}$ incidente seria mais um, entre outros, do mesmo tipo, se não tivesse sido usado como pretexto pelo Congresso paraguaio para a destituição do presidente Fernando Lugo. Em 22 de junho, cerca de 30 horas após a abertura de processo de impeachment, Lugo foi destituído pelo Congresso por 39 votos a quatro. O vice-presidente, Frederico Franco, recentemente rompido com Fernando Lugo, assumiu a presidência.

Os veículos de imprensa, nas primeiras horas após a destituição, passsaram a discutir a legalidade do ato. A Constiuição paraguaia em seu artigo 225 prevê impeachment (juicio politico) ao presidente e a outras autoridades "por mal desempenho de suas funções, por delitos cometidos no exercício de seus cargos, ou por delitos comuns". A acusação deve ser formulada pela Câmara dos Deputados por maioria de dois terços. Cabe ao Senado, por maioria absoluta de dois terços julgar o impeachment. Caso o agente seja declarado culpado, deve ser afastado de suas funções. O artigo 227

\footnotetext{
${ }^{1}$ Professora de História Contemporânea da FAPA, Doutoranda em Estudos Estratégicos Internacionais pela UFRGS, Mestre em Ciência Política pela UFRGS. E-mail: cintiavs@ mp.rs.gov.br.
} 


\section{Conjuntura Austral}

da mesma Constiuição prevê que o vice-presidente, em caso de impedimento, ausência temporária ou vacância definitiva, deve subsitituir o presidente no cargo. Em 21 de junho, a Câmara dos Deputados paraguaia votou a procedência do impeachment com 79 votos a favor, um contra e três ausências. No dia seguinte, o resultado no Senado foi de 39 votos a quatro. Horas depois, o vice-presidente Frederico Franco assumiu a presidência do Paraguai. Como se percebe, tudo se passou dentro da legalidade do ponto de vista jurídico formal. Contudo, o que chamou a atenção, mesmo dos defensores do processo de impeachment, foi a celeridade dos atos.

Um processo de impeachment tem caráter eminentemente político. Daí a correção de sua denominação em espanhol : “ juicio politico”. No Brasil, o presidente da República para sofrer impeachment tem de cometer crime de responsabilidade, um nome inadaquado para infrações de natureza política. A Constiuição de 1988, no seu artigo 85, tipifica os crimes de responsabilidade. Contudo, é fácil perceber a abrangência desses crimes - contra a existência da União, contra o livre exercício dos poderes, contra o exercício dos direitos políticos, individuais e sociais, contra a segurança interna do país, contra a probidade da administração, contra a lei orçamentária e contra o cumprimento das leis e decisões judiciais. Não seria difícil enquadrar um primeiro mandatário indesejável numa dessas categorias. No Paraguai, a cláusula "mal desempenho de suas funções" deixa mais abertas ainda as possibilidades de afastametno do agente político acusado.

A rapidez com que o processo se realizou e concluiu, contudo, projeta uma sombra sobre o afastamento de Lugo. O exame das resoluções 1198 e 122 da Câmara de Senadores do Paraguai que estabeleceram o procedimento para a tramitação do impeachment do presidente Luiz Angel González Macchi e dos ministros da Corte Suprema de Justiça Carlos Fernández Gadea, Luiz Lezcano Claude e Bonifacio Ríos Ávalos, respetivamente, previam 11 dias para o presidente e 17 dias para os ministros (Corte Suprema de Justicia, 2007, p. 527-533). Houve pressa incomum na destituição de Lugo, apesar da unanimidade tanto na Câmara dos Deputados quanto no Senado. Os procedimentos preveem produção de provas, tanto da acusação, quanto da defesa. Em 


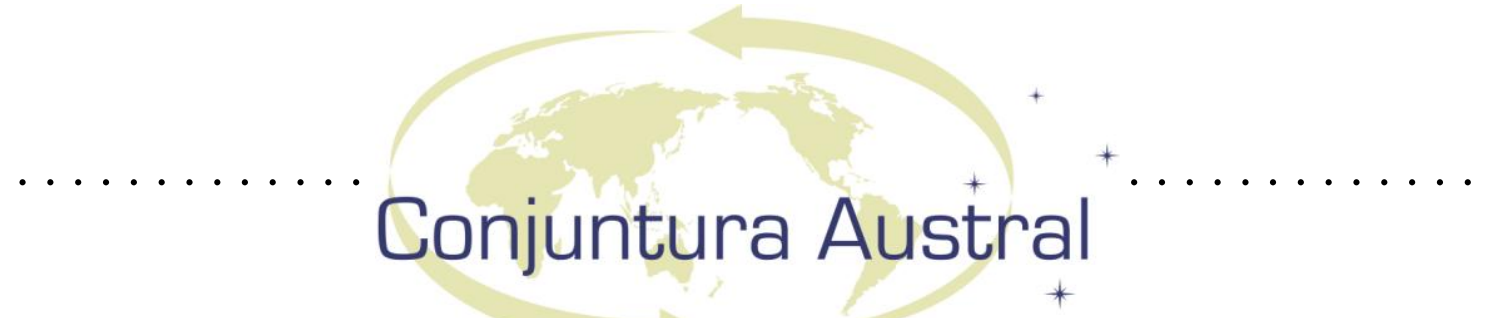

menos de 30 horas, havia pouco a se fazer, considerando ainda que Lugo estava sendo responsabilizado por atos que ocorreram longe de Assunção.

A rapidez do processo foi claramente um movimento para criar o fato consumado e evitar qualquer mobilização interna a favor do presidente deposto, o que, diante das pouco expressivas manifestações contra o impeachment, parece ter surtido o efeito desejado.

Percebe-se dois movimentos distintos nos países latino-americanos. Em alguns casos, presidentes realizam reformas constitucionais com o intento de enfraquecer os congressos e evitar qualquer controle político, como na Venezuela, Equador e Bolívia. Em outros, os congressos se valem do poder adquirido após o fim das ditaduras das décadas de 1970 e 1980, quando obtiveram amplos poderes para evitar executivos fortes, para afastar políticos eleitos democraticamente. É o caso de Honduras e, agora, do Paraguai. São duas formas distintas e eficazes para driblar a democracia. Parece que a época de rupturas com confrontos armados, militares nas ruas, prisões de dissidentes foi substituída por movimentos muitos mais sutis.

Fernando Lugo foi eleito em 20 de abril de 2008 pela Aliança Patriótica pela Mudança, uma coalizão formada por diversos partidos, dentre os quais o Partido Revolucionário Febrerista, o partido Democrata Cristão, o Partido Encontro Nacional, o Partido País Solidário, o Partido Liberal Radicial Autêntico (PLRA) e o Partido Democrático Progressista. Sua eleição encerrou 61 anos de domínio da Associação Nacional Republicana (ANR), o velho Partido Colorado. Lugo obteve 42,3\% dos votos contra 31,8\% de Blanca Avelar, do Partido Colorado e 22,8\% do general Lino Oviedo, um ex-colorado que concorreu pela União Nacional dos Cidadãos Éticos (UNACE).

No dia 20 de abril de 2008, Fernando Lugo falou à imprensa brasileira e destacou o fator que considerava mais importante para o início do seu governo: costurar alianças dentro da coalizão para garantir a governabilidade (FSP, Primeiro desafio será dar unidade na coalizão, 21 de abril de 2008). Ele tinha noção de que uma vitória apertada (os demais candidatos obtiveram quase 55\% dos votos), uma coalizão heterogênea em um país com o serviço público atrelado à máquina política colorada representava um enorme desafio. Os resultados das eleições para o Senado e para a 


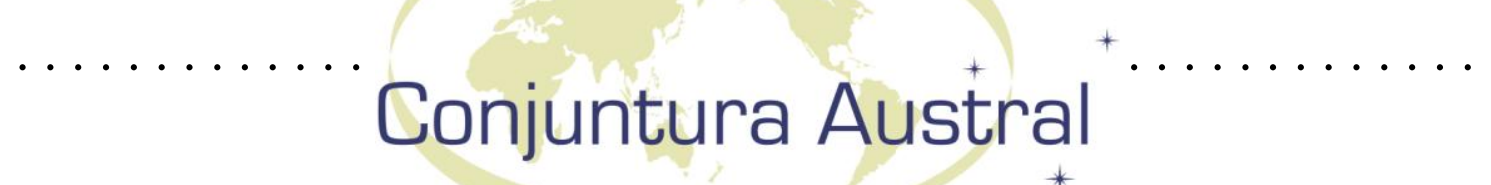

Câmara dos deputados não eram alentadores. Dos 45 senadores eleitos, 16 eram da coalizão vitoriosa, sendo que desses 14 do PLRA. Dos 29 restantes, 15 eram colorados e 9, da UNACE. Ainda há 4 membros do Partido Pátria Querida de centro direita e um do Movimento Popular Tekojoja, de esquerda. Na Câmara, dos 80 eleitos, apenas 29 eram da Aliança Patriótica pela Mudança, sendo 27 liberais. Foram eleitos 30 colorados e 15 deputados da UNACE, sendo os seis restantes de partidos menores. A Análise da OSAL de 2008 apresenta o panorama do parlamento que desitiuiu Lugo:

"Esto significa que el Partido Colorado, de orientación ideológica liberal, mantendrá un importante grupo de parlamentarios, entre los que aparecen nombres relacionados a la dictadura stronista. En segundo lugar está el PLRA, conformado por miembros cuya orientación ideológica varía, entre aquellos que son liberales de derecha hasta aquellos con tendencia más social. El tercer lugar está ocupado por los seguidores del ex general Lino César Oviedo, que responden a una concepción ideológica de derecha-fascista, los de Patria Querida, que se encuadran más dentro de la concepción ideológica liberal y los miembros del parlamento que pueden agruparse dentro de una concepción de 9 social demócratas o de izquierda son los representantes de País Solidario, Tekojoja y el Partido Democrático Progresista” (OSAL, 2008, p. 3).

Percebe-se que o fiel da balança do governo Fernando Lugo era o PLRA, de Frederico Franco. Lugo, com uma plataforma de esquerda, com contornos da Teologia da Libertação, e vinculado aos camponeses sem terra aliou-se ao Partido Liberal, para viabilizar a sua eleição. O Partido Liberal, por seu turno, utilizou a popularidade do exbispo, para apear do poder o Partido Colorado. Após o sucesso na eleição, Lugo teve muita dificuldade em compor com o Partido Liberal. Há algum tempo vinha se aproximando de políticos colorados. Após o massacre de Curuguaty, subsituiu o ministro do interior, Carlos Filizzola, do Partido País Solidário, por Ruben Candia Amarilla, ex-Procurador Geral de Justiça e ligado ao partido Colorado (La Nacion, 18 de junho de 2012, Lugi tendría que haber nombradoa un liberal o del Frente Guasu ${ }^{2}$ interior, según Yojito Franco). O chefe nacional de Polícia Paulino Rojas foi substituído em caráter interino por Arnaldo Sanabria, um dos responsáveis pelo massacre e acusado

\footnotetext{
${ }^{2}$ A Frente Guasu é a coalizão de partidos de esquerda que apoiam Fernando Lugo.
} 


\section{Conjuntura Austral}

de corrupção. Foi a gota d'água da relação de Lugo com o Partido Liberal e explica a unanimidade dos liberais na destituição do ex-bispo.

Riquelme, Vera e Villalba indicaram em 2008 o tipo de crise que poderia derrubar Lugo:

“Con este panorama, Lugo se verá obligado a negociar con los Partidos que no necesariamente tienen como prioridad temas como la Reforma Agraria, uno de los ejes centrales de la campaña del presidente electo. La redistribución de la tierra y el apoyo a la agricultura familiar campesina, entre otros, serán los más grandes desafíos del nuevo gobierno" (OSAL, 2008, p. 3).

A oposição do Partido Liberal ao partido Colorado sempre teve por objetivo a chegada ao poder, nunca foi de caráter ideológico. Tanto que antes de 2008, os liberais participaram de governos colorados. No momento em que Lugo passa a defender a reforma agrária e questionar o status dos brasiguaios, em uma direção que a imprensa mais conservadora qualifica de "bolivarização" do Paraguai, era natural a união liberal/colorados contra o ex-presidente. Além disso, os apoiadores de Lugo - jovens e camponeses - estavam decepcionados, pois quase no final do mandato houve poucos dos avanços sociais pregados na campanha eleitoral. Fernando Lugo não conseguiu manter a coalizão que o elegeu, perdendo o suporte liberal e desapontando sua base de apoio.

Com respeito ao Brasil, há que se ter em conta que duas das mais importantes promessas de campanha de Lugo se relacionavam ao país. A discussão do status dos brasiguaios e a revisão do Tratado de Itaipu.

Em 1967, foi revogada uma lei que proibia aquisição de terras por estrangeiros em faixas de fronteiras. Esse fato, aliado ao incentivo da agroindústria em detrimento da agricultura familiar, gerou uma onda migratória de brasileiros para as regiões de fronteira com o Paraná e Mato Grosso do Sul (SILVA; RODRIGUES, 2010, p. 14). A mudança de legislação deu-se no contexto de aproximação do Paraguai ao Brasil, no momento em que o último torna-se preponderante no subsistema regional (ALMEIDA MELLO, 1996, p. 11). Hoje os brasiguaios são cerca de 385 mil e são responsáveis pela produção de $60 \%$ da soja paraguaia, o que representa cerca de 30\% do PIB do país 


\section{Conjuntura Austral}

(ZAGO, 2008, p. 8). Ocorre que muitas das fazendas dos brasiguaios são ilegais, ou seja, não têm título de propriedade. Uma reforma agrária no Paraguai certamente implicaria rever o status dessas terras. Lugo propunha a reforma agrária por um lado e por outro tranquilizava o governo brasileiro e os brasiguaios quanto à salvaguarda dos seus interesses. Essa ambiguidade o enfraqueceu em duas direções. Setores mais conservadores o identificavam com Hugo Chavez e Evo Morales, apontando uma futura "bolivarização" do Paraguai (o que estaria se confirmando com o massacre de Curuguaty). Já os setores ligados às lideranças camponesas criticavam a ambiguidade do discurso e julgavam que, ao cabo de três anos e meio de governo, havia uma subordinação do presidente às demandas brasileiras.

Tudo indica que o governo Francisco Franco irá deixar de lado o discurso pró reforma agrária, até porque há grandes latifundiários no Partido Liberal e há necessidade de composição com os colorados para viabilizar o governo. O governo deposto vinha realizando um programa de regularização da situação dos brasilguaios, com o apoio brasileiro, que deve ter prosseguimento com o novo governo.

A revisão do tratado de Itaipu, contudo, ao contrário da questão dos brasiguaios, é apoiada pelas elites paraguaias. Estava igualmente nas plataforma de campanha dos colorados em 2008. O governo Lula, que durante a campanha de Lugo afirmava que o tratado não seria rediscutido, aceitou a negociação, o que foi visto como uma vitória do governo do ex-bispo. Em 25 de julho de 2009, após a Cúpula de Presidentes dos Estados Partes do Mercosul e Estados Associados, em Assunção, os presidentes Lula e Fernando Lugo assinaram um acordo para a revisão do Tratado. Esse novo acordo prevê que o valor da energia cedida pelo Paraguai ao Brasil será triplicado, passando de U\$ 120 milhões por ano para U\$ 360 milhões (O Globo, 25 de julho de 2009). Além disso, a Eletrobrás perderá a exclusividade de aquisição da energia excedente estabelecida no Tratado original e, a partir de 2023, esse excedente poderá ser negociado com outros mercados. O Acordo de Revisão do Tratado de Itaipu foi aprovado na Câmara dos Deputados e no Senado Brasileiro em 2011 e promulgado em 27 de junho de 2011 (Decreto n. 7506 de 17 de junho de 2011). Em 2012, o Paraguai 


\section{Conjuntura Austral}

receberá do Brasil 376.000.000 reais, equivalentes a 229.268.292 dólares pela cessão de energia (Diário Oficial da União, 20 de janeiro de 2012, p. 1877).

O Acordo de Revisão inclui outros projetos conjuntos. Um dos principais - a melhoria dos sistemas de transmissão de energia do Paraguai - já vem sendo implementado através dos fundos dos Focen (Fundo de Convergência Estrutural do Mercosul).

O Focen foi criado em 2004 (entrou em funcionamento em 2006) por proposta do Paraguai com o objetivo de diminuir as assimetrias entres os membros do Mercosul. Os recursos do Fundo vêm dos membros e são proporcionais aos PIB. Assim, o Brasil contribiu com a maior parte. Já a utilização dos fundos é inversa, de modo que Uruguai e Paraguai podem utilizar a maior parte dos valores (SILVA; RODRIGUES, 2011, p. 29).

Atualmente, vem sendo construída uma linha de transmissão elétrica de $500 \mathrm{kV}$ entre Itaipu e Villa Hayes, próximo a Assunção com recursos aportados pelo Brasil ao Focen (Mensagem ao Congresso Nacional, 2012, p. 325).

Frederico Franco substituiu Efrain Enríquez Gamón por Franklin Rafael Boccia Romañach na gestão paraguaia de Itaipu. Houve também substituições nas diretorias jurídicas, administrativa e de coordenação. Ao assumir em 25 e jullho último, Boccia Romañach fez uma declaração polêmica: "Não venderemos mais energia elétrica a não ser que isso nos traga recursos. Teremos utilização plena da nossa energia no Paraguai, alimentando a indústria, gerando postos de trabalho, com energia elétrica para todos os níveis e todos os setores" (Valor Econômico, Paraguai troca diretorias de Itaipu, 26 de julho, 2012). O ministro brasileiro das Minas e Energia, Edison Lobão, afirmou no dia seguinte que isso não era possível, pois qualquer mudança deve ser aprovada pelos parlamentos dos dois países. É claro que Boccia Romañach sabia disso. São recorrentes no Paraguai - e isso vale para todos os partidos - declarações anti brasileiras. O Brasil é tratado por grande parte da imprensa como um poder imperial que, historicamente, prejudica o Paraguai. Os políticos utilizam essa retórica, mas na interlocução com o governo brasileiro o tom é bastante diverso. É a velha utilização da 


\section{Conjuntura Austral}

política externa para fins internos. Isso era feito no governo Stroessner, nos governos colorados, no governo Lugo e continua no governo Franco.

A questão de Itaipu continuará, provavelmente, nas mesmas bases com o novo governo. As vitórias de Lugo com a revisão do tratado já são tratadas como vitórias do Partido Liberal. Tanto que o novo diretor de Itaipu propagandeia no site da empresa a sua própria participação na construção da nova linha de transmissão interna.

O Brasil, apesar de criticar o afastamento de Fernando Lugo, não falou oficialmente em golpe e não aprovou nenhum tipo de sanção econômica ao país. A maior sanção foi a suspensão do Mercosul até a eleição de abril de 2013. Ao contrário de Hugo Chaves e Cristina Kirchner, a presidenta Dilma Roussef assumiu posição discreta, o que reflete a importância da manutenção da ordem institucional no país vizinho para o Brasil. Na Cúpula de Brasília, quando foi selado o ingresso da Venezuela ${ }^{3}$ no Mercosul, foi Dilma que referiu-se à incômoda ausência do Paraguai enfatizando que não haveria retaliações econômicas e que "Nossa perspectiva é que o Paraguai normalize sua situação institucional interna para que possa reaver seus direitos plenos no Mercosul" (Folha de São Paulo, Dilma defende nova etapa do Mercosul com Venezuela, 1 de agosto de 2012). Uma indicação de que relação com o governo Francisco Franco será normal e as eventuais restrições ocorrerão apenas em fóruns internacionais.

\footnotetext{
${ }^{3}$ Os países do Mercosul aproveitaram a ocasião para resolver a ausência de apreciação do Senado paraguaio a respeito do ingresso da Venezuela no bloco. A Venezuela foi incorporada no dia 31 de julho de 2012, estando o Paraguai suspenso. A crítica ao afastamento de Lugo ficou deslegitimada por esse ato. As eleições no Paraguai ocorrerão em abril próximo, de modo que o ingresso da Venezuela poderia vir a ocorrer de forma que não ferisse a unidade do bloco.
} 


\section{Conjuntura Austral}

\section{REFERÊNCIAS}

Corte Suprema de Justicia. Comentario a la Consitución. Tomo III. Homenaje al décimo quinto aniversario. Assunción, 2007.

Diário Oficial da União.

Folha de São Paulo

La Nacion - Paraguay.

MELLO, Leonel Itassu Almeida. Argentina e Brasil: a balança de poder no cone sul. São Paulo: Annablume, 1996.

Mensagem ao Congresso Nacional. Brasil: Presidência da República 2012.

SILVA, André; RODRIGUES, Kamila Dalbem. Além das Assimetrias. Boletim Meridiano 47. Brasília, vol. 12, nº 125, 2011, p. 25-31.

SILVA, André; RODRIGUES, Kamila Dalbem. As relações Brasil-Paraguai com a ascensão de Fernando Lugo. Conjuntura Austral. Porto Alegre, vol. 1, nº 1, 2010, p. 13-18.

RIQUEME, Quintin; VERA, Elsy; VILLALBA, Roberto. Observatorio Social de America Latina (OSAL). Informe de Coyuntura. Paraguay, marzo-abril de 2008.

Valor Econômico

ZAGO, Evandro Farid. Revisões nas políticas interna e externa do Paraguai face ao fim do jugo colorado sobre o país. Boletim Meridiano 47. Brasília, n. 94, 2008, p. 6-9.

Artigo recebido dia 06 de agosto de 2012. Aprovado em 29 de agosto de 2012. 


\section{Conjuntura Austral}

\section{RESUMO}

A presente análise tem por objetivo explicar o recente afastamento pelo Congresso paraguaio do presidente Fernando Lugo, eleito em 2008, e avaliar as consequências dessa mudança nas relações do Paraguai com o Brasil.

\section{PALAVRAS-CHAVE}

Fernando Lugo, impeachment, relações Brasil-Paraguai.

\section{ABSTRACT}

This review aims to explain the recent impeachment of president elected in 2008 Fernando Lugo by Paraguayan Congress, and evaluate the consequences of this change in Paraguay relations with Brazil.

\section{KEYWORDS}

Fernando Lugo, impeachment, Paraguay-Brazil relations. 